\title{
El liberalismo y el proceso de organización nacional en Brasil. (Algunas líneas históricas e historiográficas para su estudio)
}

\section{Dení Trejo Barajas}

El proceso histórico que lleva a la organización de la nación brasileña en el siglo XIX, está marcado por la presencia indiscutible del liberalismo, expresión ideológica y política de la sociedad capitalista occidental que fue convirtiéndose, junto con la expansión de este sistema, en la fuente ideológica más reconocida para interpretar el mundo y, lo que era fundamental, para tratar de solucionar los problemas políticos y económicos a que los nacientes pueblos latinoamericanos se enfrentaron al iniciar su vida independiente.

$\mathrm{Si}$ bien reconocemos que el liberalismo es, a principios del siglo XIX, una herramienta ideológica revolucionaria fundamental para la organización de los nuevos estados, nos queda por aclarar, y ese será el motivo fundamental de este trabajo, cómo los diversos grupos sociales brasileños deciden impulsar un proyecto de organización nacional fundamentado ideológicamente en el liberalismo; y cómo asumen e interpretan las posturas liberales en función de sus intereses regionales y de grupo, para modificarlas finalmente y hacerlas parte de un proyecto prácticamente conservador más acorde con la estructura económica y social del Brasil esclavista, el cual pasaba además, en esos momentos, de la situación colonial a la neocolonial.

Desde el punto de vista de Florestán Fernándes, el aspecto reaccionario que asume el liberalismo en Brasil se debe precisamente al hecho de haberse permitido la hegemonía y dominio de una nueva nación sobre los pueblos que recientemente habían logrado su independencia de los antiguos imperios coloniales. Este hecho imposibilitó al país para romper con la estructura económico-social basada en el trabajo esclavo, cuestión fundamental para sostenerse en el mercado mundial.

En general, la historiografía tradicional brasileña sobre este periodo (Valladao, Octavio Tarquinio de Sousa), señala la existencia primordial de un liberalismo moderado, con líderes de mucha presencia como Evaristo da Veiga, el padre Diogo Antonio Feijó, Vasconcelos, Vergueiro, Honorio Hermeto, por señalar a los más importantes, los cuales, rechazando el absolutismo y portuguesismo de Pedro I y apoyándose en grupos de liberales radicales y en algunos sectores del ejército, habrian conseguido la abdicación del monarca en 1831. La visión más "justa" de este sector moderado sobre la radical y anárquica de los exaltados, como se les llamaba en ese entonces haciendo alusión a su desesperación por cambios más rápidos y profundos; y sobre la posición, inconsecuente ya en esos momentos, de los que pretendían restaurar el gobierno del absolutista Pedro I, llevó al poder a los moderados, que durante la difícil etapa de la regencia lograron mantener la unidad nacional y con- 
formar una elite política responsable del proceso-que llevó del federalismo al centralismo, de la etapa de fuego del liberalismo más radical al llamado "regreso", es decir, al triunfo de un conservadurismo de carácter reformista que dominaría prácticamente toda la fase del segundo Imperio.

Desde una perspectiva más contemporánea, que trata de hacer un análisis fundamentado en el estudio de la estructura económica y social del periodo, Caio Predo Junior y Nelson Werneck Sodré señalaron nuevas líneas para el análisis histórico brasileño, mostrando el papel limitado de los terratenientes esclavistas para impulsar un proyecto de carácter liberal; sin embargo, no plantearon. por qué algunos terratenientes sí asumieron un proyecto liberal radical y otros se inclinaron por un conservadurismo absolutista. Sodré deja sentado de una manera demasiado rápida el problema interregional, y me parece que tiende a encasillar, dentro del planteamiento del modo de producción esclavista y feudal, las limitaciones ideológicas del sector dominante.

Desde mi punto de vista, el problema de las clases sociales en este periodo es bastante complejo e indiscutiblemente tiene que ver con las ideas acerca de la organización nacional. El grupo de los terratenientes esclavistas, aunque tiene intereses de clase más o menos definidos, no actúa como una clase social unitaria, lo hace frente al problèma de la esclavitud, pero no frente a intereses regionales equivalentes a los suyos y que le puedan resultar competitivos. Por otra parte, su mundo de la hacienda aislada, esclavista y patriarcal resulta contradictorio para sus intereses comerciales marcados por la exportación y la importación de la cual depende.

Al igual que en el interior del grupo terrateniente nos parece que hay posiciones e intereses distintos en función de conflictos regionales y a veces hasta de carácter personal; en el interior de los sectores medios existen divergencias tales que nos hablan de la heterogeneidad de este grupo. No todos los sectores medios urbanos fueron liberales, como tiende a interpretar una cierta historiografía tradicional, aun la marxista.

En cuanto a la participación popular en la confrontación de fuerzas del periodo, trabajos como los de José Honorio Rodrígues hablan de la historia cruenta de la Regencia refiriéndose a la represión que ésta ejerció contra todos aquellos movimientos, liberales o no, que podían afectar su poder recién instaurado. En su obra, Conciliaçao e Reforma no Brasil, hace referencia a los numerosos movimientos regionales del periodo, pero fuera de estas citas de carácter general, también señaladas por otros autores, no hemos encontrado más trabajos que puedan ayudar a clarificar el papel de las fuerzas populares, su composición e influencia. Tal vez esto se deba, como dijo Octavio Tarquinio de Sousa, a que los elementos populares inconformes eran "parte de la población aún socialmente indefinida, sin posición estable, recién salidos de la esclavitud, gente desocupada de los centros urbanos o de los clanes nurales, individuos exonerados de la formación militar y aún más, de la educación civica".!

1 Octavio Tarquinio de Sousa, Diogo Antonio Feijó, cirado en Os Donos do Poder de Raymundo Faoro, Porto Alegre, Globo, 1984, p. 317. 
En fin, el estudio de los movimientos populares y su relación con el liberalismo es todavía un campo abierto para su estudio.

Trabajos tan completos como el de la História Geral da Civilização Brasileira, cuyo coordinador es Sergio Buarque de Holanda, tratan la primera mitad del siglo XIX como un proceso fundamentalmente político; sin embargo, desarrollan muy bien los procesos regionales y un factor que, a mi modo de ver, es muy importante para entender los conflictos del interior de la elite política: la lucha que se da entre un cada vez más deteriorado grupo de eclesiásticos liberales y un grupo civil de magistrados que cobran cada vez más presencia conforme avanza el proyecto conservador.

EI trabajo de Raymundo Faoro, Os Donos do Poder. Formação do Patronato Político brasileiro, resulta de gran interés para entender el proceso contradictorio entre parlamentarismo y poder ejecutivo, entre descentralización y centralización y sus posibles combinaciones, aunados al conflicto interregional.

Sin querer agotar con estas referencias historiográficas el tratamiento que se le ha dado al tema, sí me atrevería a decir que el liberalismo, sobre todo en el periodo regencial, ha sido poco estudiado, aun cuando es la etapa en la que los líderes liberales moderados construyen, de alguna manera, la autoridad política del imperio. Quizá ha recibido una mayor atención el propio conservadurismo, a través de trabajos como el de Paulo Mercadante $A$ Conciencia Conservadora no Brasil, donde se señala el carácter conciliador del conservadurismo con el inminente liberalismo económico del momento. Otros trabajos como los de João Camillo de Oliveira Torres (ver su obra La Democracia Coroada) nos plantean, desde una perspectiva conservadora, la idea de que la organización política brasileña en el siglo XIX fue una curiosa combinación entre conservadurismo y liberalismo, basada en una supuesta tendencia natural en el Brasil hacia la igualdad y el equilibrio político.

La tarea de explicarnos el liberalismo como la base ideológica sobre la cual se decide construir la nación, en un territorio donde la estructura económico-social y la dependencia externa desmienten esa posibilidad, no ha sido tarea fácil. Este trabajo, más que contribuir con una interpretación acabada del asunto está señalando algunas posibilidades y líneas para su interpretación; en este sentido, los cuestionamientos y dudas son todavía muchos.

El liberalismo en Brasil nació marcado por diversos factores que le impusieron sus propios límites: tenemos, por ejemplo, el hecho de que ciertas iniciativas económicas liberales fueron propuestas por la propia monarquía absoluta; el hecho también, de que el liberalismo brasileño tuviera una relación contradictoria con el liberalismo portugués, pues si, por un lado, este último le brindó las primeras herramientas en su lucha contra el absolutismo, por otro lado, trató de obstaculizar los afanes autonomistas de Brasil.

Por otra parte, pero actuando en el mismo sentido limitativo, tenemos el hecho de que la base social fundamental del grupo liberal e independentista fueran los grandes terratenientes esclavistas, lo cual demarcaba los alcances sociales y políticos del proyecto liberal, sobre todo en lo que se refiere a la posible ampliación del grupo de propietarios y a la liberación de la fuerza de trabajo; asimismo, el tradicional conflicto interregional entre la ciudad de Río de Janeiro y las regiones norteñas y mineras, afectadas por el dete- 
rioro de los términos de intercambio de su principal producto (el azúcar y el oro respectivamente) y por la eliminación de su papel político predominante dentro de todo el ámbito brasileño, planteó formas distintas de entender y asumir el liberalismo: finalmente estaría la aceptación, por un elemento de la propia monarquía (el príncipe heredero don Pedro de Alcántara), del postulado constitucionalista y liberal de la elite política brasileña.

Pero veamos con más detenimiento estos elementos para entender por qué el liberalismo en Brasil tiende a asumir un carácter conservador sin perder del todo su fuente reformista liberal; para entender por qué pudo desarrollarse y aceptarse, hasta por los liberales más radicales, una propuesta de organización nacional monárquica con una constitución liberal, y para entender, finalmente, por qué el liberalismo aceptó la permanencia, por casi todo el siglo, de la esclavitud pese a que las tendencias progresistas de la época señalaban la necesidad de su extinción. Tal vez la aceptación por parte de los liberales de este estado de cosas era la garantía de una relativa estabilidad, si bien por otro lado se desmentían los preceptos liberales clásicos en torno a la política y la economía.

El liberalismo brasileño tiene una de sus primeras posibilidades de desarrollo a través de las propias autoridades monárquicas coloniales, aunque es necesario señalar que esta iniciativa fue preferentemente económica. Esta tendencia innovadora dentro de la monarquía portuguesa se debió fundamentalmente a dos factores: al papel crítico en que se encontraba ésta al verse forzada a salir de la península ante la invasión napoleónica (1808), y a las presiones de Inglaterra, su antigua aliada, a la cual le interesaba sobremanera sacar partido de la situación (por un lado, garantizaba la seguridad de los monarcas en su viaje al Brasil y, por otro, obtenía ventajas económicas fundamentales, las cuales se concretaron más adelante en los tratados de 1810 , por los que Inglaterra logró privilegios con respecto a las demás naciones para exportar sus productos a Brasil; obtuvo también un trato especial para sus súbditos residentes en este territorio sudamericano, y entre otras cosas, el privilegio de explotar maderas en determinadas zonas de la costa).

Así pues, el liberalismo económico que practicó el príncipe regente don Juan (más tarde João VI) a su llegada a Brasil, se debió fundamentalmente a las presiones inglesas y a las propias debilidades del comercio portugués que, con la invasión napoleónica, se vio imposibilitado de seguir sosteniendo su monopolio, ya bastante mermado de por sí por los antiguos negocios ingleses en Portugal.

Esta primera relación entre lo que eran ideas innovadoras en el plano económico (libertad de comercio) y poder tradicional (el absolutismo de don Juan todavía no era cuestionado), hará que la concepción original y revolucionaria del liberalismo se vea mediatizada. Sólo se tomó del liberalismo lo que favorecía a la monarquía portuguesa, sin tocar para nada los aspectos políticos que pudieran lesionar su poder.

Por otra parte, en las primeras décadas del siglo XIX, el carácter centralista y privilegiado de Río de Janeiro como nueva sede de la monarquía portuguesa, genera reacomodos interprovinciales y nuevas tensiones, las cuales se expresaron en algunos casos de manera explosiva, en movimientos que plasmaron su inconformidad con el sistema monárquico y con el centralismo desarrollado por el go- 
bierno y la capital. Los objetivos más radicales de estos movimientos fueron la república y el federalismo. Ejemplo de ello serán el movimiento de 1817 en Pernambuco y la llamada Confederación del Ecuador de 1824. Ambos movimientos se dieron en el norte del país, región que en el siglo XIX sufría las consecuencias de la decadencia azucarera a causa de la competencia antillana y a la transferencia del poder económico a la región centro-sur de Brasil, donde se ubica Río de Janeiro. Podemos decir, en términos generales, que esta alternativa, hasta cierto punto radical del liberalismo brasileño, fue influida decisivamente por las experiencias federalistas de los republicanos norteamericanos e hispanoamericanos y de ellas se nutrió en su afán de encontrar un lugar no marginal dentro de la nueva organización política brasileña.

Es interesante hacer notar que, en estos movimientos, la preocupación fundamental tiene que ver con la organización política; no hay, por lo tanto, un interés decisivo por las cuestiones sociales: algunos líderes de Pernambuco o de la Confederación del Ecuador sí habían pensado en el problema de la esclavitud pero, finalmente, o estaban aislados o el abolirla no lo veían como una posibilidad real en esos momentos, ya que gran parte de su apoyo provenía de los terratenientes esclavistas. La lógica con que el liberalismo interpreta y finalmente justifica el problema de la esclavitud, la podemos captar a través de la siguiente nota, perteneciente a una declaración del gobierno provisorio de la república de Pernambuco en 1817:

¡Patriotas pernambucanos! La sospecha se ha insinuado en los propietarios rurales: ellos creen que la benéfica tendencia de la presente liberal revolución tiene por fin la emancipación indistinta de los hombres de color, y esclavos. El gobierno les perdona una sospecha, que lo honra. Nutridos en sentimientos generosos no pueden jamás acreditar que los hombres por más o menos morenos degenerasen del original tipo de igualdad; mas está igualmente convencido que la base de toda la sociedad regular es la inviolabilidad de cualquier especie de propiedad [. . .] patriotas, vuestras propiedades aun las más contradictorias al ideal de justicia serán sagradas; el gobierno pondrá medios para disminuir el mal, no lo hará cesar por la fuerza [... $]^{2}$

En esta interpretación la idea de la igualdad está subordinada a la de propiedad en aras de la permanencia social de los terratenientes. Como podemos ver, el liberalismo radical brasileño, prácticamente no tuvo que ver con planteamientos igualitaristas, lo cual, en cierto modo, no desmentía una de las características clásicas del liberalismo europeo. Será tarea de algunas grandes personalidades, la de sacar a la luz el problema de la esclavitud, aunque sin mucho éxito.

José Bonifacio de Andrada e Silva, más adelante llamado "patriarca de la independencia" e Hipólito José da Costa, redactor del periódico Correio Brasiliense, publicado en Inglaterra, representaron una opción de carácter moderado dentro del liberalismo. Para ellos, el mantenimiento de la monarquía era cuestión de principio; sin embargo, plantearon una serie de elementos de carácter social,

2 Carlos Guillerme, Mota, Nordeste 1817. Estructuras e Argumentos, São Paulo, Perspectiva, Ed. da Universidade de Sðo Paulo, 1972, p. 154. 
inusitadamente innovadores dentro del ámbito brasileño, como el de la abolición gradual de la esclavitud y el de la incorporación gradual de los indios a la civilización, haciendo además diversas proposiciones sobre la necesaria modernización de la educación. Desde luego, podemos ver aquí una influencia decisiva de la formación ilustrada de estas personalidades públicas del mundo brasileño, y no está de más señalar que seguramente los afectó el hecho de que, en esos momentos, Inglaterra ya impulsaba su campaña contra la abolición del tráfico negrero y la esclavitud, haciendo gran alarde de sus intereses humanitarios y ocultando lo suficiente los económicos. ${ }^{3}$

A pesar de que personalidades como José Bonifacio tuvieron la lucidez de plantear tempranamente el significado de la problemática de la esclavitud para Brasil (sus primeros planteamientos al respecto van a las Cortes portuguesas en 1820 ), las condiciones propias de la producción para la exportación y el peso económico y político de los esclavistas detendrá por largos años sus propuestas.

Otro de los elementos que contribuyó a la formación del Brasil Independiente es el de la revolución liberal de Portugal de 1820, la cual tendrá efectos decisivos sobre la independencia y el constitucionalismo brasileños. Una dualidad contradictoria de factores hará que aquel movimiento tenga una expresión revolucionaria y una expresión reaccionaria: la primera se plasmó en su lucha contra el absolutismo de João VI, quien había abandonado el territorio portugués en el momento de la invasión napoleónica, trasladándose al Brasil (1808-1821) con la idea de formar un nuevo imperio. Estos hechos llevaron a los insurrectos a exigir la vuelta del monarca, sólo que ahora sometido a una constitución; la segunda se reflejó en la lucha de los revolucionarios portugueses contra Brasil mismo, ya que siendo éste una colonia, les había quitado sus privilegios de metrópoli. De esta manera, si por un lado estaban luchando por implantar la monarquía constitucional (este sería el aspecto revolucionario), por el otro estaban tratando de restablecer las relaciones coloniales con Brasil (aspecto reaccionario) ya bastante deterioradas por la decadencia de los antiguos imperios coloniales y por el ascenso y la influencia del poderío inglés.

Las razones que utilizaron los constitucionalistas portugueses en su intento de recolonización fueron de carácter racista y con un tono desmedidamente autoritario y agresivo que, en vez de dar por resultado la reintegración de la excolonia a su metrópoli, lo que provocaron fue el desarrollo y la exacerbación de un cierto nativismo y autonomismo, que fueron muy explotados por la elite política en Brasil durante los acontecimientos que llevaron a la independencia. Para el estudio de este conflicto es fundamental el trabajo de Honorio Rodrígues sobre la independencia, así como la revisión de los periódicos y panfletos donde se dio un largo y reñido debate en relación a la querella portuguesa-brasileña.

Hasta aquí hemos mencionado las formas de introducción del liberalismo y las corrientes, fuerzas o personalidades que lo asumie-

3 Para Inglaterra, la eliminación de la esclavitud significaba igualdad de condiciones para la producción en todas las regiones y no que algunas, como Brasil, pudieran obtener ventajas productivas a través del trabajo forzado; por otro lado, la liberación de la fuerza de trabajo le garantizaba la ampliación del mercado de consumidores para sus productos manufacturados. 
ron de alguna u otra forma. Quedaría por revisar el proceso histórico en el cual se vieron envueltos y del cual fueron partícipes.

Todas estas expresiones, con su carga limitada o extensa de liberalismo, van confluyendo en los acontecimientos de la independencia y de la instauración del primer reinado (1822). ${ }^{4}$ Hay que reconocer que en esa coyuntura, la que permitió la independencia, lograron acuerdo todas la corrientes políticas de Brasil, desde las absolutistas hasta las liberales radicales, todas con la idea de influir en el príncipe para poder influir, a través de él, en el rumbo de los acontecimientos. Los absolutistas, con la cobertura del palacio y de la corte, irán desarrollando sus expectativas con la idea de recuperar la unión de los reinos bajo un solo monarca; los liberales, por su parte, con la idea de inclinar al príncipe heredero (que en ese momento era el príncipe regente de Brasil) hacia ciertos preceptos liberales y constitucionalistas.

Las logias masónicas, instrumento fundamental en la participación política, logran una influencia decisiva sobre el monarca. Es así que en la logia "Gran Oriente del Brasil", donde lograron una alianza temporal radicales y moderados, se decide la aclamación de don Pedro como emperador.

Es interesante explicarse, desde la perspectiva de las diversas tendencias liberales, el hecho de tal aclamación, ya que ello implicaría, a futuro, dos formas posibles de organizar el Estado: si bien radicales y moderados estaban de acuerdo en que el ser aclamado el emperador públicamente sería la evidencia de que el pueblo había delegado la soberanía de la nación en el rey (don Pedro sería rey por aclamación popular y no por derecho divino), los primeros pensaban que el monarca tenía que jurar la Constitución de antemano, en prevención de posibles desvaríos absolutistas (las provincias y los radicales de la capital pusieron el acento en este aspecto), es decir, quedaba el rey sometido a la asamblea representativa del pueblo; mientras, los moderados, con José Bonifacio como líder, impugnarían por su parte el juramento previo, ya que para ellos, el pacto era entre pueblo y monarca directamente y no necesariamente a través de un cuerpo de representantes; éste era necesario sólo para la elaboración de la Carta Magna que definiera los derechos de los ciudadanos y los campos de acción de los otros poderes, pero sin suplantar el poder fundamental del monarca aclamado popularmente (se va definiendo en esta postura una cierta preponderancia del papel del monarca).

La etapa nativista y democrática ( $s i$ así se puede llamar a su radicalismo de los primeros momentos) del nuevo emperador, se acaba pronto, acelerada además por las pugnas y conflictos entre los liberales. En la primera etapa del gobierno de Pedro I (1822), tendrá un papel fundamental José Bonifacio. Su ministerio se caracterizará por tratar de conseguir la unidad nacional frente a las resistencias todavía manifiestas de diversas provincias y por su convocatoria a la formación de la Constituyente.

\footnotetext{
- El príncipe heredero al trono de Portugal, don Pedro de Alcántara, acepta quedarse en Brasil como regente mientras su padre, João VI, regresa a Portugal ante las exigencias de los constitucionalistas. La actitud recolonizadora de los revolucionarios portugueses brinda la coyuntura para que don Pedro, en alianza con la elite política brasileña, declare la independencia.
} 
La Constituyente de 1823 logró conformar un proyecto de Carta Magna que pretendió considerar lo que eran las particularidades de Brasil. Sin embargo, estuvo comprensiblemente influida por los modelos constitucionales clásicos (el inglés y el francés). El antilusitanismo es, en este proyecto constitucional, la premisa ideológica necesaria ante el temor de la recolonización portuguesa, pero quizá lo más importante es su idea de limitar lo más posible el poder del emperador, valorizando, en contrapartida, la soberanía popular a través de su representación en el cuerpo legislativo; finalmente, el proyecto de 1823 da una importancia fundamental a los derechos políticos de los propietarios rurales, lo cual revela, según palabras de Caio Prado, su carácter clasista:

Los grandes propietarios rurales, principales responsables por la independencia, se reservaban todas las ventajas políticas de ella excluyendo de éstas a los criados domésticos, los jornaleros, los cajeros de las casas comerciales, en fin, cualquier ciudadano con rendimientos líquidos anuales inferiores al valor de 150 alqueires de harina de mandioca. En una palabra, toda la población trabajadora del país, los esclavos naturalmente incluidos. 5

En cuanto a la esclavitud, el proyecto de 1823 impulsaba ta idea del reconocimiento jurídico de los esclavos para realizar contratos, cuestión que más tarde será impugnada por los grandes terratenientes, que no aceptaban la validez de dichos contratos entre esclavos y propietarios que la ley facultaba.

Si bien el proyecto constitucional de 1823 estaba fundamentado en premisas liberales clásicas, como la de la preeminencia política de los propietarios o la limitación al poder del monarca que ahora era evidentemente constitucional, no pudo ser una realidad dado que las fuerzas conservadoras y moderadas temían que el radicalismo del legislativo exarcerbara el ánimo popular; unos por ser plenamente absolutistas y otros por temer a la "dictadura del pueblo", representada en el poder legislativo, dieron pie a lo que sería el primer golpe dado al liberalismo por el renaciente y finalmente nunca olvidado absolutismo de Pedro I. La facción de José Bonifacio acabó momentáneamente con el poder de los radicales en diversas acciones represivas; sin embargo, el grupo de los absolutistas es el que conseguirá el triunfo final con el golpe a la Constituyente de 1823, logrando que el propio patriarca de la independencia pasara a la oposición.

A pesar de encontrarse en un periodo prácticamente contrarrevolucionario, la monarquía brasileña emite, en 1824, un nuevo proyecto constitucional, que si bien modifica aspectos básicos del anterior, no deja de ser liberal en lo fundamental. Por supuesto, esta constitución eliminará los poderes que el anterior proyecto le daba al legislativo, y por contrapartida, creará un ejecutivo fuerte y con prerrogativas especiales a través del llamado cuarto poder o poder moderador, el cual le permitía al monarca ejercer el poder ejecutivo sin responsabilizarse ante la nación, sólo con la idea de la conciliación, lo cual era una manera, un tanto velada, de crear un

5 Caio Prado, Jr., Evoluczo política do Brasil e outros estudos, São Paulo, Editora Brasiliense, 1953, p. 53. 
ejecutivo con poderes extraordinarios; ${ }^{6}$ además, esta propuesta garantizaba el poder de la naciente aristocracia brasileña a través del Senado o poder minoritario y del Consejo de Estado.

Por otra parte, la nueva propuesta constitucional ampliaba las posibilidades de acceder a la representación por diputación, otorgándola no exclusivamente a los propietarios territoriales sino también a los que pudieran justificar un poder económico líquido. Por supuesto, esto no significaba una apertura de los propietarios territoriales hacia nuevos sectores sociales, más bien parecía una solución impuesta por grandes comerciantes sin propiedades territoriales que habrían quedado al margen del poder con la propuesta de 1823.

Finalmente, habría que decir que el hecho de que esta constitución fue impuesta por el monarca después de la disolución de la Constituyente de 1823 y en contra de las expectativas federalistas de varias provincias, creó un ambiente de desgaste alrededor de la figura real, cuestión que se complicó con su insistencia en retomar el trono portugués y que finalmente lo llevaría a la abdicación en 1831 .

Las luchas que se generan después de la abdicación por el poder político y para lograr la organización y la unidad nacional, se expresan no en el enfrentamiento dicotómico entre liberalismo y conservadurismo, sino en las pugnas, rencillas y rivalidades interregionales, las cuales, en función de intereses inmediatos, pueden asumir o rechazar casi indistintamente algunos aspectos liberales o conservadores.

Podemos decir, de hecho, que en este momento son todavía inexistentes los partidos y sólo nos encontramos frente a facciones de orígenes sociales y políticos similares. En este sentido, parecen pesar mucho más las contradicciones entre regiones que las contradicciones entre ideales político-sociales, aunque esto no quita que haya elites regionales que pugnen por un ideal político específico.

Así tenemos que, mientras Río de Janeiro es mayoritariamente monárquico, otras regiones, como el norte, han sido escenario constante de revueltas de carácter republicano. Por supuesto, esta contradicción no lo dice todo, pues los republicanos del norte podían ser igualmente esclavistas, pero sus intereses económico-políticos afectados por el ascenso de la región centro-sur, la podían llevar a enfrentarse con las aspiraciones tradicionalmente centralistas, hegemonistas y monárquicas de Río de Janeiro.

En términos generales podemos decir que el liberalismo dominó en gran parte de las acciones de la elite intelectual y política del Brasil; sin embargo, las condiciones estructurales (el poder económico de los grandes terratenientes esclavistas y de los comerciantes), imposibilitaron que, de manera radical, un proyecto de carácter liberal en su totalidad, tuviera éxito, de ahí que coexistiera éste con elementos que contradecían sus postulados clásicos.

Hubo también un factor que propició el carácter del liberalismo brasileño: el temor de la elite a los exabruptos populares. La Revo-

6 Tal parece que la idea fundamental de Benjamín Constant, respecto al poder moderador como factor de equilibrio entre un poderoso poder parlamentario y un ejecutivo delegado en un gabinete de ministros, en el caso brasileño se veía modificado al quedar dicho poder y el ejecutivo mismo en manos del monarca. 
lución francesa, como hecho histórico, no como ideal político social, había pesado más negativa que positivamente.

Dentro de este contexto, la monarquía aparecía a los ojos de los liberales como una necesidad transitoria, mientras la sociedad y la economía evolucionaban hasta hacer posible la existencia de la república. Según ellos, había que crear las condiciones para el advenimiento de la democracia y de la república, y esto sólo lo podía hacer sin romper la unidad nacional, el poder centralizador y carismático de un monarca: acabar con la esclavitud lentamente para no afectar los intereses de los comerciantes y de los propietarios; crear nuevos propietarios medianos o pequeños mediante leyes que favorecieran la inmigración europea, principalmente anglosajona; crear una fuerza de trabajo sustitutiva del esclavo; acabar con la dispersión regional.

Esos son los razonamientos de varios de los liberales de la época, aun de los más radicales, de que aceptaran la monarquía como opción política para la organización de la nación.

Los arranques absolutistas de Pedro I y las pugnas entre regiones y entre grupos de poder, hicieron que las expectativas liberales que no se cumplían emergieran constantemente, motivando conflictos y enfrentamientos que tuvieron su etapa más efervescente en el periodo de la regencia, después de la abdicación de Pedro I (1831) y antes del ascenso al trono de Pedro II (1840). La regencia será así la etapa en que, lograda la dimisión del monarca el 7 de abril de 1831 , se exalten los preceptos federales del liberalismo y se convoque a una modificación de la Constitución, lo cual se logra el 6 de mayo, gracias a los trabajos de la regenerada Cámara de Diputados que consagra la federación, suprime el poder moderador y el Consejo de Estado y establece finalmente la condición electiva y temporal del Senado que hasta entonces era prácticamente vitalicio; por último, transforma los consejos generales en asambleas legislativas provinciales. Tal parecía que con la Regencia se procuraba el triunfo del liberalismo; sin embargo, la reforma a la constitución debía pasar por el Senado, donde dominaban los conservadores, cuestión que implicó nuevos enfrentamientos entre una y otra Cámara.

Los enfrentamientos entre liberales exaltados (que veían la coyuntura favorable para establecer la federación dentro de la monarquía y algunos hasta la república) y liberales moderados (que finalmente eran los que habían asumido el poder con la instauración de la regencia y que, por lo tanto, pensaban que la tarea que seguía era la de guardar el orden después de haber logrado la dimisión del monarca y la regeneración del legislativo) llevaron a una situación inestable con numerosas insurrecciones liberales: la del Ceará, de 1831 a 1832; la de Pernambuco, de 1832 a 1835; la del Pará, de 1835 a 1837; la de Bahía, de 1837 a 1838; la de Maranhao, de 1838 a 1841, y finalmente la de Río Grande do Sul, de 1835 a 1845.

Con el enfrentamiento entre exaltados (esta facción reunía propietarios de tierras y de esclavos del nordeste y representantes de las capas medias urbanas) y moderados (aristocracia rural del sudeste) se abre también la posibilidad de que vuelvan a entrar al escenario los conservadores (altos funcionarios y comerciantes portugueses, así como la nobleza formada desde el periodo joanino) que se encontraban concentrados en el Senado. La coyuntura les permite a estos últimos rechazar el proyecto de reforma de la Constitución 
proveniente de la Cámara de Diputados, sobre todo, en lo que se refiere a la eliminación de su propio poder.

La imposibilidad de proseguir por el camino reformista hace que la regencia vea como única salida contra el Senado la del golpe de Estado, lo cual permitiría a la Cámara de Diputados asumir funciones de asamblea nacional con la idea de que votase inmediatamente la Constitución de Pouso Alegre, publicada bajo la dirección del padre José Bento Leite Ferreira de Melo, y que reproducía prácticamente la Constitución imperial pero con las reformas propuestas por la Cámara anteriormente. El golpe planeado por la regencia y bajo la autoridad del padre Diogo Antonio Feijó no tuvo éxito ante el legalismo de Honorio Hermeto, uno de los lideres moderados que, deslindado del grupo de Feijó, comienza a plantear una escisión que lo llevará más adelante a la formación del Partido Conservador. Feijó se ve precisado a renunciar y el Senado sólo aprueba, de entre las reformas propuestas por la Cámara, la de restablecer la Regencia Una (compuesta por un solo miembro) y la de sustituir los consejos generales por asambleas provinciales. La estabilidad no se logra, continúan también los enfrentamientos entre restauradores y liberales hasta que, el 12 de octubre de 1832, es autorizado el "Ato Adicional" (promulgado en 1834), obra de conciliación entre las posturas liberales y conservadoras y que aprueba la disolución del Consejo de Estado, además de las reformas ya aprobadas por el Senado. Sin embargo, reservaba la designación del presidente provincial al gobierno central y sacrificaba, además, las amplias autonomías municipales. Cosa curiosa, el "Ato Adicional" apoyado por los liberales, era contradictorio al Código de Procedimiento Criminal, aprobado poco tiempo después que el "Ato Adicional" por la misma Cámara, pero sin darle demasiada importancia cuando, en realidad, representaba un verdadero avance en el sentido liberal; "el Código del Proceso Criminal establecía, en esencia, la justicia democrática, esto es, la justicia confiada en la más amplia medida a las magistraturas de elección popular". ${ }^{7}$

En el Código cumplía un papel fundamental el juez de paz, cargo de elección popular para la impartición de justicia; sin embargo, los hechos y las necesidades políticas de la regencia, bajo el mando de Feijó, modificaron este contenido democrático del Código al supeditar a dichos jueces al gobierno central y hacerlos partícipes de la organización de las guardias provinciales que ahora quedaban a su arbitrio y al de los propietarios rurales. La democracia no era posible en una organización social donde la mayor parte de la población estaba sujeta al poder de unos cuantos dueños de grandes extensiones de tierra y de esclavos. La modificación del Código y del mismo "Ato Adicional" sería imprescindible más adelante.

El "Ato Adicional" significó el impulso de una política de conciliación por parte de los liberales moderados que, nuevamente en el poder, abren el camino al conservadurismo. Esta nueva política que ellos mismos llamarían "regreso" está claramente explicada por Bernardo de Vasconcellos, uno de los eminentes liberales del periodo de la regencia, que así justificaba su cambio de actitud:

1 Sergio Buarque de Holanda, Historia Geral de Civilizacão Brasileira, Säo Paulo, DIFEL, 1985, t. II, vol. 2, p. 27. 
Fui liberal, entonces la libertad era nueva en el país y estaba en las aspiraciones de todos, pero no en las leyes, no en las ideas prácticas, el poder lo era todo: fui liberal. Hoy, sin embargo, es diverso el aspecto de la sociedad: los principios democráticos todo ganaron y mucho comprometieron; la sociedad que entonces corria riesgo por el poder, lo corre ahora por la desorganización y por la anarquía. Como entonces lo quise, ahora quiero servirla, y por eso soy regresista. No soy tránsfuga, no abandono la causa que defendí en los días de peligro o de debilidad: la dejaré en el día en que tan seguro sea su triunfo que hasta el exceso la comprometa. ${ }^{8}$

Esta cita del líder del parlamentarismo brasileño marcará el inicio del ascenso de un conservadurismo que se concilia con algunas de las propuestas liberales, pero que está decidido, a su vez, a acabar con todo movimiento que "altere el orden" o que se declare liberal, republicano o federal. Por eso, para varios autores, el fin de la regencia y el inicio del segundo reinado es la etapa del "regreso", y a la política de transacción entre medidas liberales y conservadoras, la denominan "conciliación”.

El periodo de regencia llegó a sus últimos momentos cuando los liberales se dieron cuenta de que la única forma de recobrar el poder, ahora en manos de los conservadores, sólo era posible retomando, de nueva cuenta, el ideal monárquico. La cohesión que los liberales lograron alrededor de la solución monárquica, con su proyecto de declarar mayor de edad al heredero de la corona (en ese entonces con sólo 14 años), no sólo revela el oportunismo de una oposición que para no morir estaba dispuesta a eliminar de su camino los principios legales que supuestamente la sustentaban, sino que también expresa la idea de que sólo el régimen imperial servía como marco institucional para que no se destruyera la debilitada unidad política brasileña. Progresistas y regresistas, como fueron llamados entonces liberales moderados y conservadores, respectivamente, coincidieron finalmente en la necesidad de adelantar la mayoría de edad del emperador para que asumiera cargo y poder, restaurando, de esa manera, la autoridad monárquica debilitada durante la regencia e impulsando un nuevo proceso centralizador a través del restablecimiento del poder moderador, del Consejo de Estado y de la disminución de las prerrogativas de las asambleas legislativas provinciales, proceso que se concretó en la Ley interpretativa del "Ato Adicional" (1840) y en la reforma al Código del Proceso Criminal (1841), promulgados después de la caída del primer gabinete liberal del segundo imperio.

Podríamos concluir diciendo que el proyecto liberal de organización del estado nacional fue llevado a cabo por la facción moderada de los liberales - después de haber desplazado del poder tanto a los exaltados como a los restauradores - y por los conservadores, partido al cual finalmente se adhirieron varios liberales; ello con un proyecto de organización nacional que se fundamentaba en una relación de supeditación al mercado externo (británico) que privilegiaba a los sectores propietarios esclavistas y exportadores brasileños y que pretendía acabar, en el plano político, con la "etapa de caos" (presencia de los sectores populares provinciales) a que había

${ }^{8}$ Alfredo Valladão, Da aclamacão a maioridade, São Paulo, Brasiliana, 1939, p. 104-105. 
llevado el liberalismo político y la descentralización del periodo regencial. El "regreso" estaba en marcha, el segundo imperio sería su expresión, fuera con gabinetes liberales o conservadores. El dicho popular "no hay nada más parecido a un conservador que un liberal en el gobierno", expresaba claramente cómo el pueblo entendía que la política estaba trazada desde arriba por una elite que por momentos podía estar fuertemente dividida, pero que, en general, su política de privilegio a uno u otro grupo oligárquico, no modificaba gran cosa la situación social.

\section{BIBLIOGRAFIA}

Andrada e Silva, José Bonifacio, "Representacão a Assamblea Geral Constituinte e Legislativa do Imperio do Brasil Sobre a Escravatura", y "Apontamentos para a Civilização dos Indios Bravos do Imperio do Brasil", en O Patriarcha da Independência, São Paulo, Nacional, 1939.

Buarque de Holanda, Sergio, Historia Geral da Civilização Brasileira, São Paulo DIFEL, 1985, tomo 2, vol. II.

Faoro, Raymundo, Os Donos do Poder. Formação do Patronato Político Brasileiro, Porto Alegre, Globo, 1984.

Fernándes, Florestán, La Revolución burguesa en Brasil, México, Siglo XXI, 1978.

Halperin Dongui, Tulio, Reforma y disolución de los Imperios Ibéricos. 1750-1850, Madrid, Alianza, 1985.

Mercadante, Paulo, A Conciếncia Conservadora no Brasil, Río de Janeiro, Saga, 1965.

Mota, Carlos Guilherme, Nordeste. 1817. Estruturas e Argumentos, São Paulo, Perspectiva, 1970.

Prado Caio, Junior, Evolução Política do Brasil e Outros Estudos, São Paulo, Brasiliense, 1953.

Rodrígues, José Honorio, Independencia: Revolução e Contra-revolução. A Evolução Política, Río de Janeiro, Francisco Alves, 1975.

Sodré, Nelson Werneck, As Razões da Independência, Río de Janeiro, Civilização Brasileira, 1969.

Sousa, Octavio Tarquinio de, História de dois Golpes de Estado, Río de Janeiro, José Olympio, 1939.

—, Diogo Antonio Feijó. (1784-1843), Río de Janeiro, J. Olympio, 1942.

- José Bonifacio, emancipador del Brasil, México, Fondo de Cultura Económica, 1945.

Torres João, Camillo de Oliveira, A Democracia Coroada. Teoría Política do Imperio do Brasil, Río de Janeiro, Vozes, 1964.

Valladão, Alfredo, Da Aclamação á Maioridade, São Paulo, Brasiliana, 1939. 